\title{
Analysis on the Relationship Between Landscape Ecology and Urban Ecological Landscaping
}

\author{
Yifei Li \\ School of Art and Design \\ New Rural Construction Research Center \\ Wuhan University of Science and Technology \\ Wuhan, China 430065
}

\author{
Mingying Li \\ School of Art and Design \\ New Rural Construction Research Center \\ Wuhan University of Science and Technology \\ Wuhan, China 430065
}

\begin{abstract}
With the development of economy and the acceleration of urbanization, more and more people pay more attention to the urban greening in the city. In the planning and design of urban gardens, it is especially necessary to take into account the necessity of keeping the continuity and completeness of landscape ecological processes and patterns in landscape ecology. Landscape ecology correctly expounds the mutual problems between man and the natural landscape. Ecocity is a product of mutual coordination and mutual promotion of social economy and ecological environment under the modern civilized science and technology, and is the future goal of urban construction and direction.
\end{abstract}

Keywords-landscape ecology; urban landscaping; relationship

\section{INTRODUCTION}

In recent years, with the development of urban landscape construction and the in-depth study of landscape ecology, the theory, principles and methods of landscape ecology have begun to guide the construction of landscape architecture. How to combine landscape ecology with urban landscape construction and build an ecological city and a garden ecological city has become a hot issue in today's urban landscape construction. Landscape ecology is a science that studies the effects of landscape spatial structure and morphological characteristics on biological activities and human activities. It focuses on resources, environment and management at the landscape and regional scales. The application of landscape ecology in landscape construction makes the urban landscape construction more in line with the ecological significance, promotes the ecological construction of the garden city, and embarks on the road of sustainable development.

\section{THEORETICAL BASIS FOR LANDSCAPE ECOLOGY}

\section{A. Diversity and Heterogeneity of Landscape}

The so-called landscape diversity refers to different types of landscapes; the so-called landscape heterogeneity refers to the degree of change of the landscape itself. The former can reflect the complexity of the landscape to a large extent, and includes the landscape pattern diversity and functional diversity; the latter determines the diversity of the landscape pattern, which makes the ecosystem of people's living environment more stable and flexible.

\section{B. The Theory of Island Biogeography}

The basic theory of landscape biology is the theory of island biogeography. The two processes of species extinction and immigration determine the abundance of island species. Usually the ecological space of an island is very limited. The more species on the island is, the less the number of species that may be newly moved, and the greater the possibility of extinction of existing species may be. Therefore, for any island, the more species on the island, the smaller the migration rate, the greater the extinction rate, and the greater the likelihood of species changes. However, the abundance remains relatively unchanged, and the species mobility and extinction rate of the island are the same, which makes the number of species on the island reach a dynamic balance to some extent.

\section{THE ROLE OF URBAN LANDSCAPING}

\section{A. Urban Landscaping Can Improve People's Quality of Life}

In urban life, the level of greening is closely related to people's quality of life. Urban landscaping can create a living space for ecological rest and relieve the city's traffic pressure and also relax people's life pressure.

\section{B. Urban Landscaping Can Beautify the Urban Landscape}

Urban garden landscape can beautify the urban environment, the vegetation itself has a decorative effect, and it will change with the seasons, which has a higher aesthetic. In the city, it can also alleviate the suppression of buildings and introduce natural atmosphere to urban people. In addition, plants can also absorb car exhaust and carbon dioxide in urban life.

\section{Urban Landscaping Can Protect the Environment}

In cities, landscaping can also absorb noise and dust Vegetation has photosynthesis, which can absorb carbon dioxide in urban air, and can reduce urban greenhouse effect and improve urban atmosphere. In addition, landscaping can also reduce dust in the city. In the garden, the surface of the 
plant is not smooth, and there is a sap that absorbs dust. Reduce sound wave transmission and reduce noise pollution. Not only that, landscaping can provide people with coolness in summer, improve air humidity and regulate urban temperature. Reasonable garden landscape can greatly improve the ecological environment of the city.

\section{ThE CONTENT OF URBAN ECOLOGICAL GARDEN}

People need to study the relationship between ecosystems and landscape ecosystems based on theories of ecology, landscape science, landscape ecology, botany and related urban ecology. Its purpose is to coordinate the relationship between ecological landscape, the harmony between man and nature, the pursuit of sustainable development, and the solution to the contradiction between the growth of human needs and the limited supply of nature. A virtuous cycle of ecological restoration can ensure the sustainable development of the economy and society and the steady improvement of people's lives, thus promoting the construction and development of ecological cities. Ecological garden advocates the construction of urban biocommunities based on the principle of ecological diversity, so that urban ecological gardens can develop in a stable and coordinated manner, maintain the ecological balance of the city, and enrich the diversity of urban biology. In this sense, biodiversity should be an important indicator to measure the perfection and stability of urban ecological gardens.

\section{APPLICATION OF LANDSCAPE ECOLOGY IN URBAN ECOLOGICAL GARDEN CONSTRUCTION}

\section{A. The Patch-corridor-matrix Theory}

The usual landscape structure units can be divided into three types: patch, corridor and matrix. The patch is a nonlinear surface area different from the matrix, is the basic structure and functional unit of the landscape, and is the scale of the urban green space system planning. The theory of scale, shape and edge effects provides an ecological basis for the positioning, regulation and morphology of parks, plazas and small gardens. The background on either side of the corridor is different, and it is considered as a linear or banded plaque. Corridor has functions such as linkage, filtration, barrier, habitat and material source. It is mainly used to guide the planning and design of urban roads and riverside linear roads, including linear, selection of greening tree species, ecological constraints and supporting relationships. The matrix is the landscape with the largest connectivity and maximum landscape range. It determines the original nature of the landscape and plays the most important role in landscape dynamics. In the construction of urban landscapes, the composition of the matrix determines the diversity and stability of the system. In the construction of urban landscapes, efforts should be made to improve the urban greening area, and it is also conducive to the construction of ecological garden cities.

\section{B. The Corridor}

The corridor in the landscape is a narrow strip that is distinctly different from the base on either side. It has a dual nature: on the one hand, it has the property of separating different parts of the landscape, as a barrier between the landscapes, on the other hand it connects different parts, and it serves as a channel. Numerous studies have shown that for strip corridors, the center and internal environment, including the diversity of internal species and marginal species, varies with the width of the corridor due to its wide bandwidth. This has important reference significance for the design of urban landscaping system corridors, provides a theoretical basis for the planning of urban roads and riverline linear zones, including the shape of linear green land, the selection of tree species, and the restricted and supportive relationships of ecology between lines and surfaces.

\section{Matrix}

The landscape elements in the matrix are of the largest area, the strongest connectivity, and the strongest control function of landscape. Porosity and connectivity are the primary structural components of the substrate. As a background, it controls the "island fragmentation" effect that affects the material and energy in the habitat patches, enhances or buffers the habitat patches; it also controls the connectivity of the entire landscape and affects the species migration of the patches.

\section{Plant Configuration}

In order to meet plant diversity and the principles of plant biology and ecology, geographic latitude and altitude must first be considered. Second, consider the environmental impact of plant species, the resistance to the same types of pollutants, the ability to purify soil pollution and water pollution. Finally, the harmful effects of plants must also be given enough attention. Some plants have a lot of beneficial functions while having a certain negative effect. The impact of the ecological benefits of abiotic buildings is more negative. According to the basis of environmental science research, the perception of the environment by plant is multifunctional. Compared with the ordinary white wall, the average temperature of the wall covered with vines differs by about $5{ }^{\circ} \mathrm{C}$. Therefore, in the greening construction, not only the appropriate plants should be selected, but also the grouping effect between different plants should be determined. At the same time, increase the amount of greening, pay attention to the cultivation of large trees and vertical greening. Limit and coordinate the space of herbs, vines, and semishrubs; limit and coordinate the distribution of slow-growing trees and fast-growing plants; limit and coordinate the proportion between evergreen trees and shrubs and deciduous broad-leaved tree and shrubs and conifers. Not only does the heterogeneity increase in the same green patches, but the diversity of landscape elements is enhanced.

\section{E. Landscape Connectedness and Landscape Connectivity}

Landscape ecology believes that the landscape connectedness is one of the criteria for distinguishing between the matrix and the batch. It is a landscape element synthesized by the spatial structure and used to determine the landscape structure. Landscape connectivity refers to the link 
between landscape function and ecological process, used to measure the characteristics of functional landscapes. For example, the landscape connectivity between the size and shape of the patch, the presence of corridors, and the crossover frequency between different types of fences. Landscape connectivity reflects the degree of development through the degree of patch between species migration or other ecological processes. Therefore, an element with high connectivity does not necessarily have high connectivity, and an element with less connectivity does not necessarily have small connectivity. In the communities that are connected between organisms, if the landscape connectivity is large, it will be much easier to exchange, breed and survive in the biomes, and the resistance will be smaller. On the contrary, the resistance to exercise will become larger and survival will be more difficult. Corridor is one of the manifestations of the landscape connectedness elements. Studies have shown that corridors play an important role in the alternation, migration and survival of biomes.

\section{IMPROVING THE APPLICATION OF LANDSCAPE ECOLOGY IN URBAN ECOLOGICAL GARDENS}

\section{A. Paying Attention to Suburban Ecological Construction and Strengthening the Construction of Urban Green Space System}

Landscape ecological cities such as scattered gardens such as nurseries, residential green spaces, street green spaces, parks, etc., are known as plaques of urban buildings similar with "Habitat Island". If there is not enough connectivity between the islands, it will greatly affect the migration of various species. Therefore, in the urban construction planning, the relevant personnel must take all the habitat islands in the urban area as part of the urban green space planning, and take appropriate measures to connect the scattered landscapes, formed a networked and systematic garden eco-city, which not only provides a wider habitat for living things, but also promotes the mutual migration of animals and plants inside and outside the city. For example, the metropolitan area in the suburbs of the city has much better natural conditions than the urban center. Urban builders can build green corridors around the city, build shelter forests to enrich the biodiversity of the suburbs.

\section{B. Strengthening the Protection of Biodiversity}

Each landscape unit in a city has different functions. Different plant communities increase the heterogeneity of the city. For example, urban builders place special ornamental plants in specific landscape areas, and build unique landscapes in the city, defines a certain cultural atmosphere, giving people a visual aesthetic enjoyment and spiritual enjoyment. Urban residents have different cultural levels and different cultural needs. Only by ensuring the diversity of urban biology can the city cover various landscape groups, reduce the urban residents' psychological repression from the crowded urban buildings, let urban residents get psychological relaxation on landscape setting

\section{CONCLUSION}

In the construction of urban ecological gardens, it is necessary to rationally select different types of plants and determine the distribution pattern among different plants in time. In green space ecosystems, the ratio between shrubs, herbs, trees, and vines should be better coordinated and limited, coordinate and limit the slow-growing and fastgrowing tree species, deciduous shrubs and evergreen shrubs, broad-leaved and coniferous plants, increase the heterogeneity between green patches of the same species. Ecology provides a clear reference for goals and principles for landscape architecture construction. It draws on two disciplines of landscape ecology and garden construction, creating a living environment with more optimized quality, purification and beautification. In the construction of urban ecological gardens, "landscape ecology" has been widely used, which has provided the corresponding theoretical guidance for the perfect combination of research and practice in landscape architecture.

\section{REFERENCES}

[1] Shen Dehui, Li Yeqing. Application of Landscape Ecology Principle in Ecological Garden Construction [J]. Heilongjiang Science and Technology Information, 2011. (in Chinese)

[2] Yan Shujun, Hong Wei, Wu Chengzhen, et al. Application of landscape ecology in urban ecological garden construction [J]. Fujian Forestry Science and Technology, 2010. (in Chinese)

[3] Gu Xinren, Liu Yuanqiu. Discussion on the application of landscape ecology principle in conservation of urban biodiversity - the countermeasures of urban garden construction [J]. Acta Agriculturae Universitatis Jiangxiensis, 2001. (in Chinese) 